\title{
Experimentally determined low temperature fluid-antigorite trace element partitioning data
}

\author{
CROTTY, CATHERINE ${ }^{1}$, VAN HINSBERG, VINCENT ${ }^{1}$
}

${ }^{1}$ Department of Earth and Planetary sciences McGill

University. 3450 University Street, Montreal, Canada,

H3A OEA, catherine.crotty@mail.mcgill.ca

Serpentinites are common components of oceanic lithosphere and a dominant fluid source in subduction processes. Quantitative understanding of fluid compositions is required to better understand fluid related subduction processes, as hydrothermal fluids are key agents in element redistribution during water-rock interactions. If partitioning data between the mineral and the fluid at relevant conditions are known, these can be used to quantitively reconstruct the trace composition of fluids, as secondary minerals that grow in equilibrium with a fluid, and which have not been subsequently overprinted, retain a signature of the composition of this fluid. Partitioning experiments were carried out under conditions that represent the sub ocean floor mafic to ultramafic crust. A saline, reduced fluid doped with trace elements was reacted in sealed quartz glass tubes with mineral chips of natural antigorite or San José olivine, both of known composition. This approach represents a forward reaction and a re-equilibration. The quartz glass tubes were placed in steel autoclaves and heated to 300 to $400^{\circ} \mathrm{C}$. Major and trace elements were determined by WDS-EPMA and LAICPMS respectively and electron imaging used to characterise run products. Here, we present the results of these experiments and the observed controls on the partition coefficients in terms of temperature and fluid composition, and we assess the applicability of antigorite for reconstructing the composition of the fluid from which it formed.

Serpentinites have been preserved across the geological record, with the oldest known serpentines in Isua, SW Greenland that are $3.8 \mathrm{Ga}$. The ability to calculate the composition of hydrothermal fluid reservoirs in oceanic crust will ultimately allow for fingerprinting of the elemental flux into oceans by deep-sea venting; and thereby an indirect view into the compositional changes of the ocean through time. 